Fixed Point Theory, 22(2021), No. 2, 685-712

DOI: $10.24193 /$ fpt-ro.2021.2.45

http://www.math.ubbcluj.ro/ nodeacj/sfptcj.html

\title{
ON INERTIAL TYPE ALGORITHMS WITH GENERALIZED CONTRACTION MAPPING FOR SOLVING MONOTONE VARIATIONAL INCLUSION PROBLEMS
}

\author{
L.O. JOLAOSO*, M.A. KHAMSI**, O.T. MEWOMO*** AND C.C. OKEKE**** \\ *School of Mathematics, Statistics and Computer Science, University of KwaZulu-Natal, \\ Durban, South Africa \\ E-mail:216074984@stu.ukzn.ac.za \\ ** Department of Applied Mathematics and Sciences, Khalifa University, \\ Abu Dhabi, United Arab Emirates \\ E-mail: mohamed.khamsi@ku.ac.ae \\ ${ }^{* * *}$ School of Mathematics, Statistics and Computer Science, University of KwaZulu-Natal, \\ Durban, South Africa \\ E-mail:mewomoo@ukzn.ac.za \\ **** School of Mathematics, Statistics and Computer Science, University of KwaZulu-Natal, \\ Durban, South Africa \\ E-mail:215082178@stu.ukzn.ac.za
}

\begin{abstract}
In this article, we introduced two iterative processes consisting of an inertial term, forward-backward algorithm and generalized contraction for approximating the solution of monotone variational inclusion problem. The motivation for this work is to prove the strong convergence of inertial-type algorithms under some relaxed conditions because many of the existing results in this direction have only achieved weak convergence. We note that when the space is finite dimension, there is no disparity between weak and strong convergence, however this is not the case in infinite dimension. We provide some numerical examples to justify that inertial algorithms converge faster than non-inertial algorithms in terms of number of iterations and cpu time taken for the computation. Key Words and Phrases: Accelerated algorithm, fixed point problem, inertial term, inverse strongly monotone, maximal monotone operators, zero problem.
\end{abstract}

2020 Mathematics Subject Classification: 47H06, 47H09, 47J05, 47J25, 47H10.

Acknowledgement. The authors sincerely thank the anonymous reviewer for his careful reading, constructive comments and fruitful suggestions that substantially improved the manuscript. The first and fourth authors acknowledge with thanks the bursary and financial support from Department of Science and Innovation and National Research Foundation, Republic of South Africa Center of Excellence in Mathematical and Statistical Sciences (DSI-NRF COE-MaSS) Doctoral Bursary. The second author would like to acknowledge the support provided by the Deanship of Scientific Research at King Fahd University of Petroleum and Minerals for funding this work 
through Project No. IN171032. The third author is supported by the National Research Foundation (NRF) of South Africa Incentive Funding for Rated Researchers (Grant Number 119903). Opinions expressed and conclusions arrived are those of the authors and are not necessarily to be attributed to the CoE-MaSS and NRF.

\section{REFERENCES}

[1] H.A. Abass, K.O. Aremu, L.O. Jolaoso, O.T. Mewomo, An inertial forward-backward splitting algorithm for approximating solutions of certain optimization problems, J. Nonlin. Funct. Anal., 2020(2020), Article ID 6.

[2] A.A.N. Abdou, B.A.S. Alamri, Y.-J. Cho, L.-J. Zhu, Iterative approximations with hybrid techniques for fixed points and equilibrium problems, Filomat, 30(7)(2016), 1997-2009.

[3] T.O. Alakoya, L.O. Jolaoso, O.T. Mewomo, Modified inertial subgradient extragradient method with self-adaptive stepsize for solving monotone variational inequality and fixed point problems, Optimization, (2020), https://doi.org/10.1080/02331934.2020.1723586.

[4] F. Alvarez, H. Attouch, An inertial proximal method for monotone operators via discretization of a nonlinear oscillator with damping, Set Valued Anal., 9(2001), 3-11.

[5] H. Attouch, A. Cabot, Convergence of a relaxed inertial forward-backward algorithm for structured monotone inclusions, Applied Math. Optim., 38(2019).

[6] H. Attouch, J. Poypouquet, The rate of convergence of Nestrov's accelerated forward-backward method is actually faster than $\frac{1}{k^{2}}$, SIAM J. Optim., 26(2016), 1824-1836.

[7] H.H. Bauschke, P.L. Combettes, A weak-to-strong convergence principle for Fejer-monotone methods in Hilbert spaces, Math. Oper. Res., 26(2001), 248-264.

[8] L.C. Ceng, Approximation of common solutions of a split inclusion problem and a fixed point problem, J. Appl. Numer. Optim., 1(2019), 1-12.

[9] Y. Censor, T. Elfving, A multiprojection algorithm using Bregman projections in a product space, Numerical Algorithms, 8(2)(1994), 221-239.

[10] W. Cholamjiak, P. Cholamjiak, S. Suantai, An inertial forward-backward splitting method for solving inclusion problems in Hilbert spaces, J. Fixed Point Theory Appl., 20(42)(2018).

[11] W. Cholamjiak, N. Pholasa, S. Suantai, A modified inertial shrinking projection method for solving inclusion problems and quasi nonepansive multivalued mappings, Comput. Appl. Math., (2018), 1-25.

[12] P.L. Combettes, V.R. Wajs, Signal recovery by proximal forward-backward splitting, Multiscale Modeling and Simulation, 4(4)(2005), 1168-1200.

[13] F. Cui, Y. Tang, Y. Yang, An inertial three-operator splitting algorithm with applications to image inpainting, Appl. Set-Valued Anal. Optim., 1(2019), 113-134.

[14] Q.L. Dong, D. Jiang, P. Cholamjiak, Y. Shehu, A strong convergence result involving an inertial forward-backward algorithm for monotone inclusions, J. Fixed Point Theory Appl., 19(4)(2017), 3097-3118.

[15] Q.L. Dong, H.B. Yuan, Y.J. Cho, Modified inertial Mann algorithm and inertial CQ-algorithm for nonexpanive mappings, Optim. Lett., (2017), doi: 10.1007/211590-016-1102-9.

[16] H.W. Engl, M. Hanke, A. Neubauer, Regularization of Inverse Problems, Kluwer Academic Publishers Group, Dordrecht, The Netherlands, 1996.

[17] B. Halpern, Fixed points of nonexpanding maps, Bull. Amer. Math. Soc., 73(1967), 591-597.

[18] D. Han, H.K. Lo, Solving non-additive traffic assignment problems: a descent method for cocoercive variational inequalities, Eur. J. Oper. Res., 159(2004), 529-544.

[19] L.O. Jolaoso, K.O. Oyewole, C.C. Okeke, O.T. Mewomo, A unified algorithm for solving split generalized mixed equilibrium problem and fixed point of nonspreading mapping in Hilbert space, Demonstr. Math., 51(2018), 211-232.

[20] Y. Kimura, K. Nakajo, Strong convergence for a modified forward-backward splitting method in Banach spaces, J. Nonlinear Var. Anal., 3(2019), 5-18.

[21] P.L. Lions, B. Mercier, Splitting algorithms for the sum of two nonlinear operators, SIAM Journal on Numer. Anal., 16(6)(1979), 964-979. 
[22] G. López, V. Martin-Marquez, F. Wang, H.-K. Xu, Forward-backward spliting methods for accretive operators in Banach spaces, Abstr. Appl. Anal., 2012(2010), Article ID: 109236.

[23] P.E. Maingé, Approximation methods for common fixed points of nonexpansive mappings in Hilbert spaces, J. Math. Anal. Appl., 325(2007), 469-479.

[24] C. Martinez-Yanes, H.-K. Xu, Strong convergence of the CQ method for fixed point processes, Nonlinear Anal., 64(2006), 2400-2411.

[25] A. Meir, E. Keeler, A theorem on contraction mappings, J. Math. Anal. Appl., 28(1969), 326329.

[26] O.T. Mewomo, F.U. Ogbuisi, Convergence analysis of iterative method for multiple set split feasibility problems in certain Banach spaces, Quaest. Math., 41(2018), no. 1, 129-148.

[27] U. Mosco, Convergence of convex sets and of solutions of variational inequalities, Advances in Math., 3(1969), 510-585.

[28] A. Moudafi, M. Oliny, Convergence of a splitting inertial proximal method for monotone operators, J. Comput. Appl. Math., 155(2003), 447-454.

[29] M.O. Osilike, D.I. Igbokwe, Weak and strong convergence theorems for fixed points of pseudocontractions and solutions of monotone type operator equations, Comput. Math. Appl., 40(2000), 559-567.

[30] B.T. Polyak, Introduction to Optimization, Translations Series in Mathematics and Engineering, Optimization Software, New York, Optimization Software Inc. Publications Division, 1987.

[31] B.T. Polyak, Some methods of speeding up the convergence of iteration methods, U.S.S.R. Comput. Math. Math. Phys., 4(5)(1964), 1-17.

[32] Y. Song, X. Liu, Convergence comparison of several iteration algorithms for the common fixed point problems, Fixed Point Theory Appl., (2009), Article ID: 824374, p. 1-13.

[33] T. Suzuki, Moudafi's viscosity approximations with Meir-Keeler contractions, J. Math. Anal. Appl., 325(2007), 342-352.

[34] M. Tsukada, Convergence of best approximation in a smooth Banach space, J. Approx. Theory, 40(1984), 301-309.

[35] F. Wang, H.-K. Xu, Approximating curve and strong convergence of the CQ-algorithm for the split feasibility problem, J. Inequal. Appl., Vol. 2010, Article ID: 102085, 2010.

Received: November 13, 2019; Accepted: September 14, 2020. 
